\title{
Application of Kansei engineering and data mining in the Thai ceramic manufacturing
}

\author{
Chaiwat Kittidecha ${ }^{1} \cdot$ Koichi Yamada ${ }^{2}$
}

Received: 30 June 2015 / Accepted: 8 January 2018/Published online: 16 January 2018

(C) The Author(s) 2018. This article is an open access publication

\begin{abstract}
Ceramic is one of the highly competitive products in Thailand. Many Thai ceramic companies are attempting to know the customer needs and perceptions for making favorite products. To know customer needs is the target of designers and to develop a product that must satisfy customers. This research is applied Kansei Engineering (KE) and Data Mining (DM) into the customer driven product design process. KE can translate customer emotions into the product attributes. This method determines the relationships between customer feelings or Kansei words and the design attributes. Decision tree J48 and Class association rule which implemented through Waikato Environment for Knowledge Analysis (WEKA) software are used to generate a predictive model and to find the appropriate rules. In this experiment, the emotion scores were rated by 37 participants for training data and 16 participants for test data. 6 Kansei words were selected, namely, attractive, ease of drinking, ease of handing, quality, modern and durable. 10 mugs were selected as product samples. The results of this study indicate that the proposed models and rules can interpret the design product elements affecting the customer emotions. Finally, this study provides useful understanding for the application DM in KE and can be applied to a variety of design cases.
\end{abstract}

Keywords Kansei engineering $\cdot$ Data mining $\cdot$ WEKA $\cdot$ Ceramic

\section{Introduction}

Nowadays, the product design and development has become more complexity and fast changes (Yang et al. 1999). Every company competing in market has to focus on this issue, and they have improved their products to enhance consumer satisfaction. A product with aesthetic design that matches with customer preference was chosen especially when product alternatives are similar in terms of functions and price (Tang et al. 2013). According to product design and development, Kansei Engineering (KE) has been used to fulfill subjective needs and preferences of customers. KE methodology aims to translate human psychology, such as feelings and emotions, into appropriate

Chaiwat Kittidecha

chaiwatkit@hotmail.com

1 Rajamangala University of Technology Lanna, 128 Huay Kaew Road, Muang, Chiang Mai 50300, Thailand

2 Nagaoka University of Technology, 1603-1, Kamitomiok, Nakaoka, Niigata 940-2188, Japan product design attributes, such as size, shape and other engineering characteristics (Nagamachi 2001). This method has ability to test the different feeling and shows their relation with characteristics of real productions requirements (Huang et al. 2012). It has been successfully applied in various design domains, such as running shoes (Shieh and Yeh 2013), chocolate snacks (Schütte 2013), E-commerce sunglasses (Chuan et al. 2013), beverage bottle (Luo et al. 2012) and booth show (Huang et al. 2011). However, because a product is composed of many elements, it requires separated KE study conducted on each component. Consequently, it takes long time and extreme costs (Pitaktiratham et al. 2012). Data mining is one of the "Knowledge Discovery in Databases" processes. DM can be used to explore numerus volumes of data to discover the hidden patterns and the interactions of highly complex dataset (Zayed et al. 2013). This technique has been used widely in the areas of science and engineering and it has been called as a modern analysis methodology (Natek and Zwilling 2013); e.g. an intelligent system for complex process monitoring (Rezki et al. 2016), a maintenance 
policy (Faghihinia and Mollaverdi 2012) and future behavior of stock price (Mehmanpazir and Asadi 2017). The concept of DM has been applied in KE such as truck cab design (Yang et al. 2008), sofa (Pitaktiratham et al. 2012) and mobile phone (Jiao et al. 2003). In this study, we proposed the integration of KE and DM in order to find the relationships between the emotions and the product attributes. Ceramic is one of most consumer perception product that plays a vital role in design development. Many Thai ceramic companies are attempting to know the customer needs and perceptions for making favorite products, but lacking of formal methodology. The purpose of this study is to determine user feelings related to the features of ceramic design in the Thai manufacturing by KE and DM as a primary study. The findings from this research would increase customer satisfaction and help product designers.

\section{Theoretical background}

\section{Kansei engineering}

$\mathrm{KE}$ is known as "translating technology a consumer's feeling and image for a product into design elements" (Nagamachi 1995). KE is performed by Kansei and the engineering field to evaluate human sensibility and produce the product that customers need and satisfy (Nagamachi 2007). The aim of KE is method to develop new product design according to consumer feeling or emotion. KE System is used to analyze the product attributes that influence on the customer emotion as shown in Fig. 1. Consequently, the features of products can be designed regarding to the emotion and feeling. KE has been applied in various industries in supporting designers to understand consumer. $\mathrm{KE}$ is obtained through experiments on customer emotions and feelings affected the physical product and finding the interaction between the psychological feeling and the product element.

\section{Data mining}

DM can use to explore, analyze and discover the structure and rules from tremendous volumes of data (Berry and Linoff 1997). Data mining is generally used for prediction and description. There are many data mining tools such as

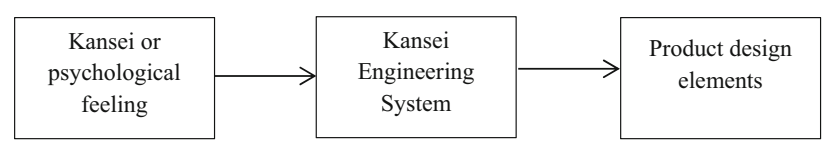

Fig. 1 A diagram of a process of Kansei engineering system (Nagamachi 2007) classification, clustering, association rule mining, attribute selection and visual interactive page (Kaya et al. 2014).

\section{The J48 algorithm}

The $\mathrm{J} 48$ decision tree is one of classified tools by creating a decision tree using the attribute values. J48 algorithm is a modified version of C4.5 and ID3 algorithm implemented through Waikato Environment for Knowledge Analysis (WEKA) software works with discrete and continuous variables and generates the trees (University of Waikato 2015). Decision trees summarize the relationship between attributes and the class of an object in a branching tree structure. The tree consists of decision nodes, chance nodes and end nodes. At each node in the decision tree, the estimation criteria are used to select relevant input variables for prediction (Wikipedia 2015a).

\section{Association rule mining}

Association rules mining is "a data mining method to find the interesting association or correlation among a large set of data items"' (Jiao et al. 2003). It is used to identify the significant rules in databases using the support and confidence measurements. The support and confidence are used to select interesting rules (Wikipedia 2015b). The support reveals how of frequently the items appear in the database. The confidence reveals the number of times the true statements. Apriori algorithm is the best-known algorithm and widely used in association algorithm. Class association rule (CAR) is one of tools in association rule mining with the specified classes (Lia et al. 2002). CAR was used instead of general association rules in this study.

\section{Confusion matrix}

A confusion matrix is a table with each column represents the instances in a predicted class, while each row represents the instances in an actual class (Wikipedia 2015c). Each cell in the table represents the number of true positives (TP), false negatives (FN), false positives (FP) and true negatives (TN) as shown in Table 1. From the confusion matrix the accuracy was calculated as follows.

Table 1 Confusion matrix

\begin{tabular}{lll}
\hline Actual class & \multicolumn{2}{l}{ Predict class } \\
\cline { 2 - 3 } & Yes & No \\
\hline Yes & TP & FN \\
No & FP & TN \\
\hline
\end{tabular}


Accuracy $=\frac{\mathrm{TP}+\mathrm{TN}}{\mathrm{TP}+\mathrm{TN}+\mathrm{FP}+\mathrm{FN}}$.

\section{Methodology}

This study applied KE and Data mining based on model procedure as presented by Schütte and Eklund (2005). The procedures of this study represented in Fig. 2. This procedure is presented as follows.

\section{Choice of domain}

A mug was selected as the product domain. The sample size of the study was 37 participants for training set $(67 \%$ of all the data) and 16 participants for test set (33\% of all the data). The ratio $70-30$ is often used in data mining for split of the data set (Analysis Services 2017). The participants were Thai people who used the mug for a long time.

\section{Span the semantic space}

Kansei words were collected from advertisements, internet videos, magazines, literature reviews. In the initial stage, a total of around 170 different words describing could be extracted. Some of unclear words were omitted in the screening step. After discussions with the professionals and experts in product design from Rajamangala University of Technology Lanna (Thailand), 6 words highly relevant were finally determined, namely, attractive, ease of drinking, ease of handing, quality, modern and durable.

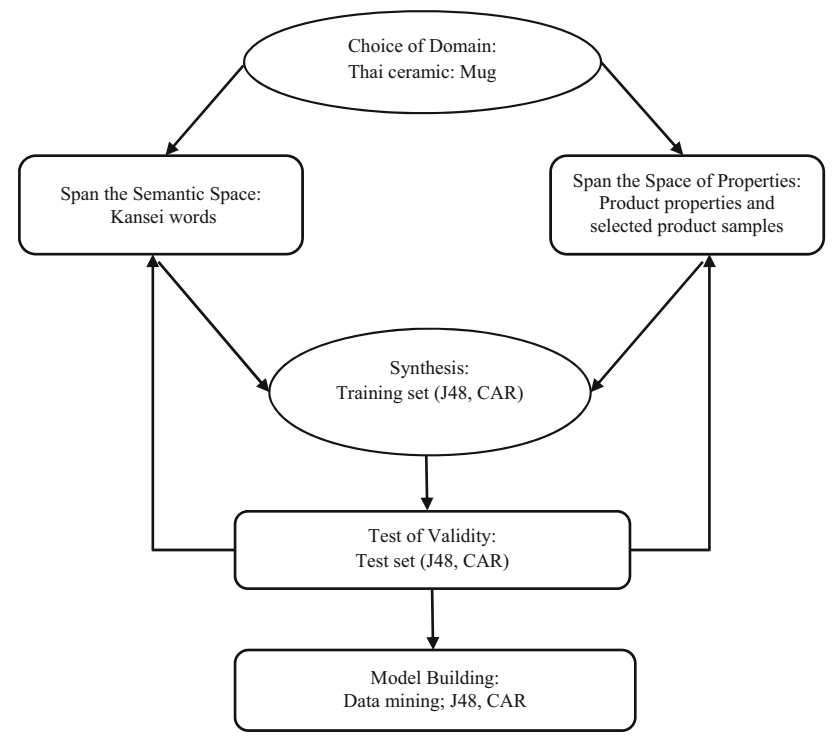

Fig. 2 Research methodology

\section{Span the space of properties}

We conducted an interview with 3 ceramic manufacturing experts to obtain complete description of the mug appearance. The external feature of mug can be deconstructed as 6 design attributes or items, namely, body, handle, foot, lip, color and pattern. For spanning the space of properties, 6 different aspects with 24 different properties in total, which are enough to represent the whole mug designs, were identified as shown in Table 2. Finally, a total of $10 \mathrm{mug}$ sample images which would cover the whole design space were selected as the product image questionnaires as shown in Fig. 3. Table 3 shows the product properties of the mug samples. For example, Mug 1 has cylinder body, loop handle, non-foot, non-lip, pain color and non-pattern.

\section{Synthesis}

\section{Data collection process}

Firstly, the questionnaire is constructed by using the 5 score Likert scale which ranged from 5 that means strongly agree, 4 means agree, 3 means undecided, 2 means disagree and 1 means strongly disagree. Constructed questionnaires were used to perform a survey. The participants were given a brief introduction about how to fill in the survey and described about the meaning of Kansei words. They were asked questions: How do you feel about the sample " $x$ " for Kansei word " $x$ "? The product samples images were ordered randomly.

\section{Synthesis}

WEKA freeware developed by the University of Waikato was conducted to analysis the DM Technology. We also used the decision trees technique J48 and CAR as best suited for data analysis. Using the tenfold cross validation method in WEKA, the data was analyzed by each of the models, and the best one was chosen. Each model was evaluated on a training set. The accuracy is calculated for $\mathrm{J} 48$, whereas the support and confidence are used for CAR.

\section{Test of validity}

To validate the relationships between Kansei words and product properties, a separate data was used on the test set. The available data will divide into two sets: a training set and a testing set. Training set is the one that is used for the training of the algorithm. These are 370 for each kansei word, which are the questionnaire results for 10 sample mugs by 37 participants. A test set is only used to test the performance of a trained model. The test data are 160 for 
Table 2 Product properties identified

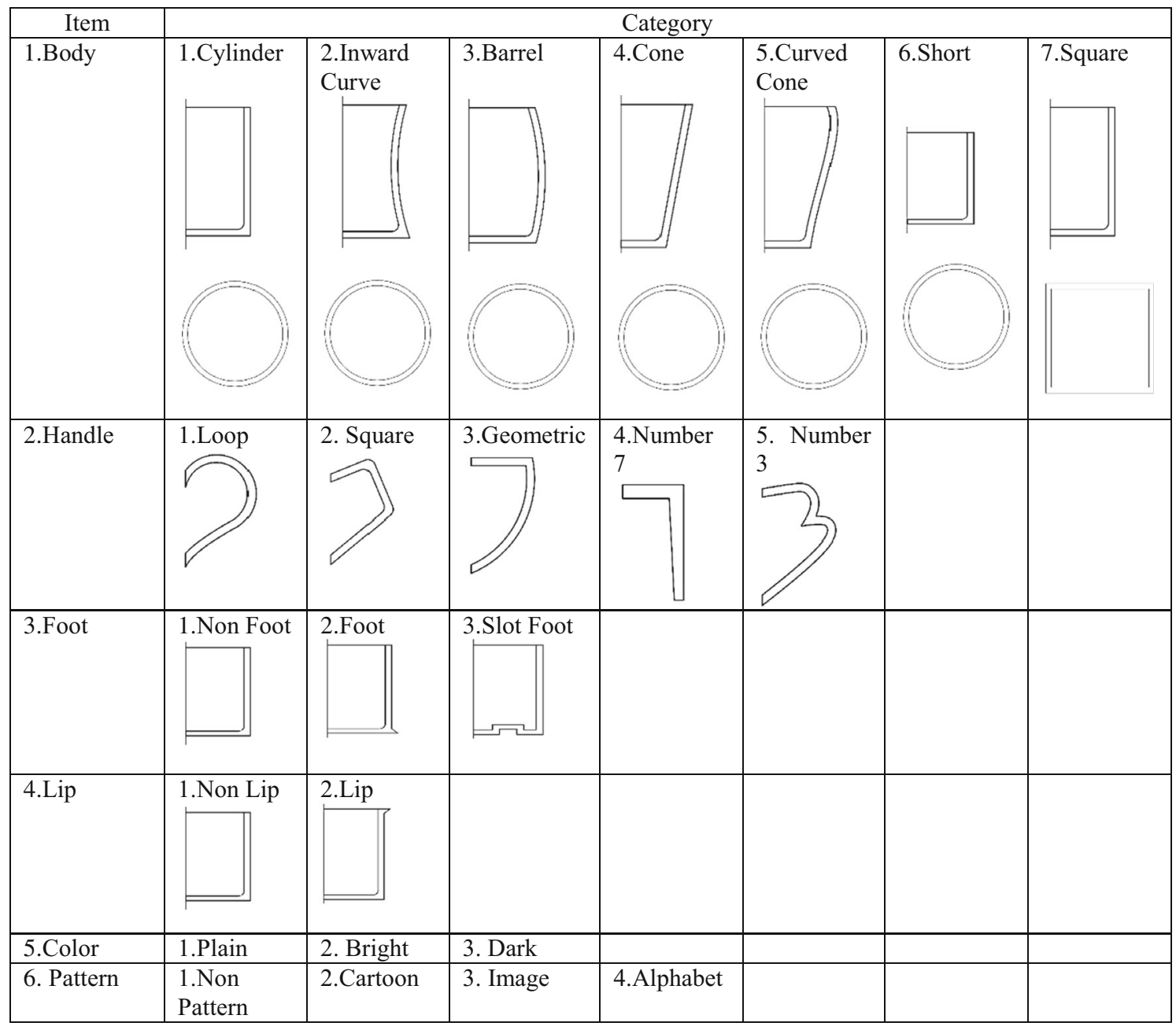

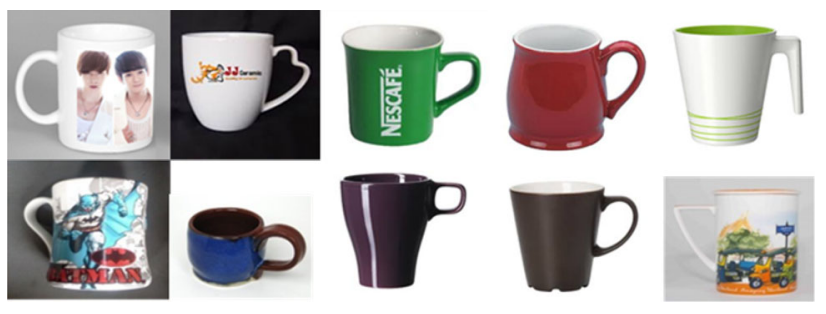

Fig. 3 Mug samples selected for evaluation. Top row from left: Mug 1-5. Bottom row from left: Mug 6-10

each kansei word, which are the questionnaire results for 10 sample mugs by 16 participants. The evaluation measures were evaluated again.

\section{Model building}

The data acquired from the synthesis step are presented in a relational model. Models are proposed that relate between each of Kansei words and product attributes. The most important factor among product attributes was determined as the decision tree by J48 algorithm. Normally, the decision tree is graphically revealed with hierarchical structures that include a root node, branches, and leaf nodes. Each Kansei word is set as the decision attribute and the product properties (items and categories) are set as conditional attributes. In the analysis by $\mathrm{J} 48$, the most important factors were determined by the leaf nodes that are the high degree of emotions (from agree to strongly agree level). CAR was used to understand the relationships between product attributes and emotions from the strongest to the weakest relationship for each of Kansei word. The most important 
Table 3 The product properties of the mug samples

\begin{tabular}{|c|c|c|c|c|c|c|c|c|c|c|c|c|c|}
\hline \multirow{3}{*}{$\begin{array}{l}\text { Product } \\
\text { sample }\end{array}$} & \multicolumn{13}{|c|}{ Product properties } \\
\hline & \multicolumn{8}{|l|}{ Body } & \multicolumn{5}{|c|}{ Handle } \\
\hline & Cylinder & $\begin{array}{l}\text { Inwar } \\
\text { Curve }\end{array}$ & & Barrel & Cone & $\begin{array}{l}\text { Curved } \\
\text { Cone }\end{array}$ & Short & Square & Loop & Square & Geometric & $\begin{array}{l}\text { Number } \\
7\end{array}$ & $\begin{array}{l}\text { Number } \\
3\end{array}$ \\
\hline Mug1 & $\mathrm{x}$ & & & & & & & & $\mathrm{x}$ & & & & \\
\hline Mug2 & & & & & & $\mathrm{x}$ & & & & & & & $\mathrm{x}$ \\
\hline Mug3 & & & & & & & & $\mathrm{x}$ & & $\mathrm{x}$ & & & \\
\hline Mug4 & & & & $\mathrm{x}$ & & & & & $x$ & & & & \\
\hline Mug5 & & & & & $\mathrm{x}$ & & & & & & & $\mathrm{x}$ & \\
\hline Mug6 & & $\mathrm{x}$ & & & & & & & $\mathrm{x}$ & & & & \\
\hline Mug7 & & & & & & & $\mathrm{x}$ & & $x$ & & & & \\
\hline Mug8 & & & & & & $\mathrm{x}$ & & & & $\mathrm{x}$ & & & \\
\hline Mug9 & & & & & $\mathrm{x}$ & & & & $\mathrm{x}$ & & & & \\
\hline Mug10 & $\mathrm{x}$ & & & & & & & & & & $\mathrm{x}$ & & \\
\hline \multirow{3}{*}{$\begin{array}{l}\text { Product } \\
\text { sample }\end{array}$} & \multicolumn{13}{|c|}{ Product properties } \\
\hline & \multicolumn{3}{|l|}{ Foot } & \multicolumn{2}{|l|}{ Lip } & \multicolumn{4}{|l|}{ Color } & \multicolumn{4}{|c|}{ Pattern } \\
\hline & $\begin{array}{l}\text { Non } \\
\text { Foot }\end{array}$ & Foot & $\begin{array}{l}\text { Slot } \\
\text { Foot }\end{array}$ & $\begin{array}{l}\text { Non } \\
\text { Lip }\end{array}$ & Lip & $\begin{array}{l}\text { Plain } \\
\text { Color }\end{array}$ & $\begin{array}{l}\text { Bright } \\
\text { Color }\end{array}$ & & $\begin{array}{l}\text { Park } \\
\text { Color }\end{array}$ & $\begin{array}{l}\text { Non } \\
\text { Pattern }\end{array}$ & Cartoo & on Image & Alphabet \\
\hline Mug1 & $\mathrm{x}$ & & & $\mathrm{x}$ & & $\mathrm{x}$ & & & & & & $\mathrm{x}$ & \\
\hline Mug2 & $\mathrm{x}$ & & & $\mathrm{x}$ & & $\mathrm{x}$ & & & & & $\mathrm{x}$ & & \\
\hline Mug3 & $\mathrm{x}$ & & & & $\mathrm{x}$ & & $\mathrm{x}$ & & & & & & $\mathrm{x}$ \\
\hline Mug4 & & $\mathrm{x}$ & & & $\mathrm{x}$ & & $\mathrm{x}$ & & & $\mathrm{x}$ & & & \\
\hline Mug5 & $\mathrm{x}$ & & & $\mathrm{x}$ & & $\mathrm{x}$ & & & & $\mathrm{x}$ & & & \\
\hline Mug6 & $\mathrm{x}$ & & & $\mathrm{x}$ & & & $\mathrm{x}$ & & & & $\mathrm{x}$ & & \\
\hline Mug7 & & $\mathrm{x}$ & & $\mathrm{x}$ & & & & $\mathrm{x}$ & & $\mathrm{x}$ & & & \\
\hline Mug8 & $\mathrm{x}$ & & & $\mathrm{x}$ & & & & $\mathrm{x}$ & & $\mathrm{x}$ & & & \\
\hline Mug9 & & & $\mathrm{x}$ & $\mathrm{x}$ & & & & $\mathrm{x}$ & & $\mathrm{x}$ & & & \\
\hline Mug10 & $\mathrm{x}$ & & & $\mathrm{x}$ & & & $\mathrm{x}$ & & & & $\mathrm{x}$ & & \\
\hline
\end{tabular}

rules also determined by the high degree of emotions (from agree to strongly agree level). Product designers can design product attributes related to the customer emotions which are retrieved from these results. For example, the combination of product attributes that modeled for the emotions or Kansei word of attractive.

\section{Results and discussion}

In this study, J48 classifier technique and CAR are proposed for evaluating the relationships between Kansei words and product properties. All the models are trained and tested, the results obtained are recorded. Firstly, we selected the best decision tree structure for each emotion

Table 4 Training and test data decision tree with different confidence factors

\begin{tabular}{lcllllll}
\hline Model & Confidence factor & \multicolumn{2}{l}{ Accuracy $(\%)$} & & \\
\cline { 3 - 8 } & & Attractive & Ease of drinking & Ease of handing & Quality & Modern & Durable \\
\hline Training data 1 & 0.25 & 34.59 & 31.08 & 27.84 & 36.22 & 30.27 & 34.59 \\
Training data 2 & .04 & 34.59 & 28.38 & 26.76 & 36.22 & 29.73 & 34.95 \\
Training data 3 & 0.6 & 35.40 & 28.65 & 26.49 & 36.22 & 29.73 & 37.03 \\
Test data & & 35.00 & 38.75 & 36.25 & 37.27 & 36.25 & 40.00 \\
\hline
\end{tabular}


model as shown in Table 4. The training and test data were 370 and 161 instances, respectively. Training datal was selected for predictive model ease of drinking, ease of handing and modern, whereas training data 3 was selected for model of attractive and durable because theirs accuracy were the best. The effects of product properties on customer emotion were mapped as shown in Figs. 4, 5, 6, 7, 8 and 9. For example, Fig. 4 shows the map indicates that the product properties such as pattern, body and handle affect the emotion of attractive results significantly. Table 5

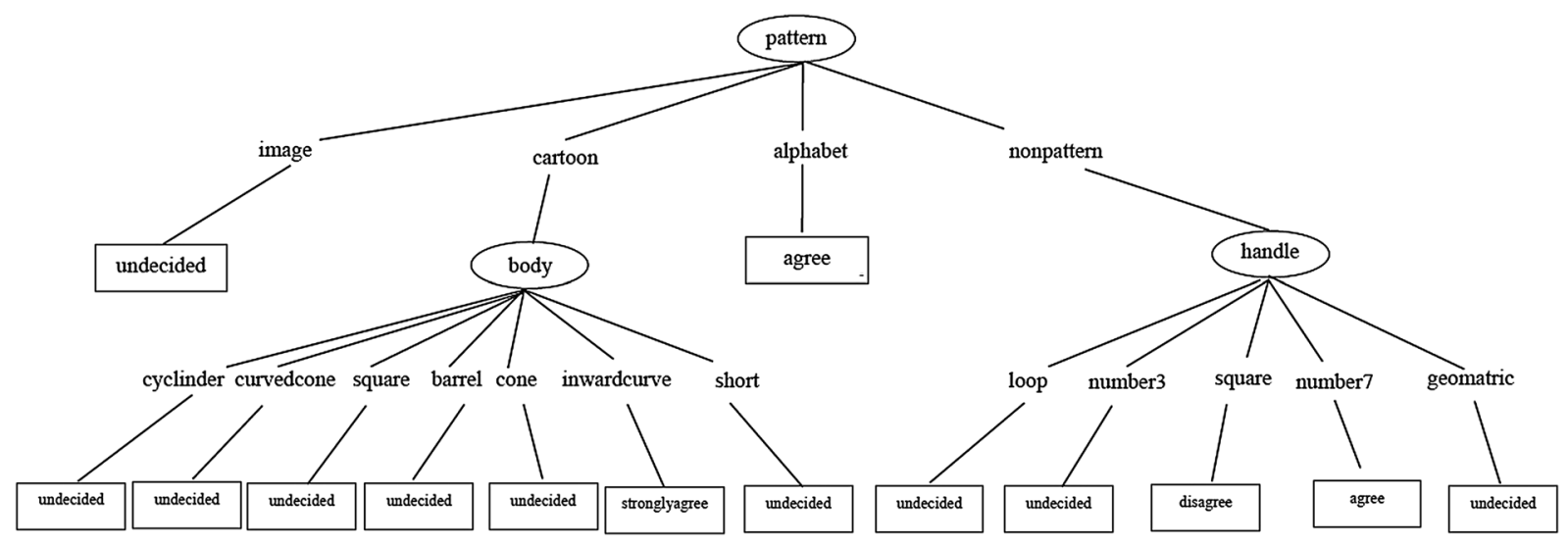

Fig. 4 Decision tree classifier for the emotion of attractive

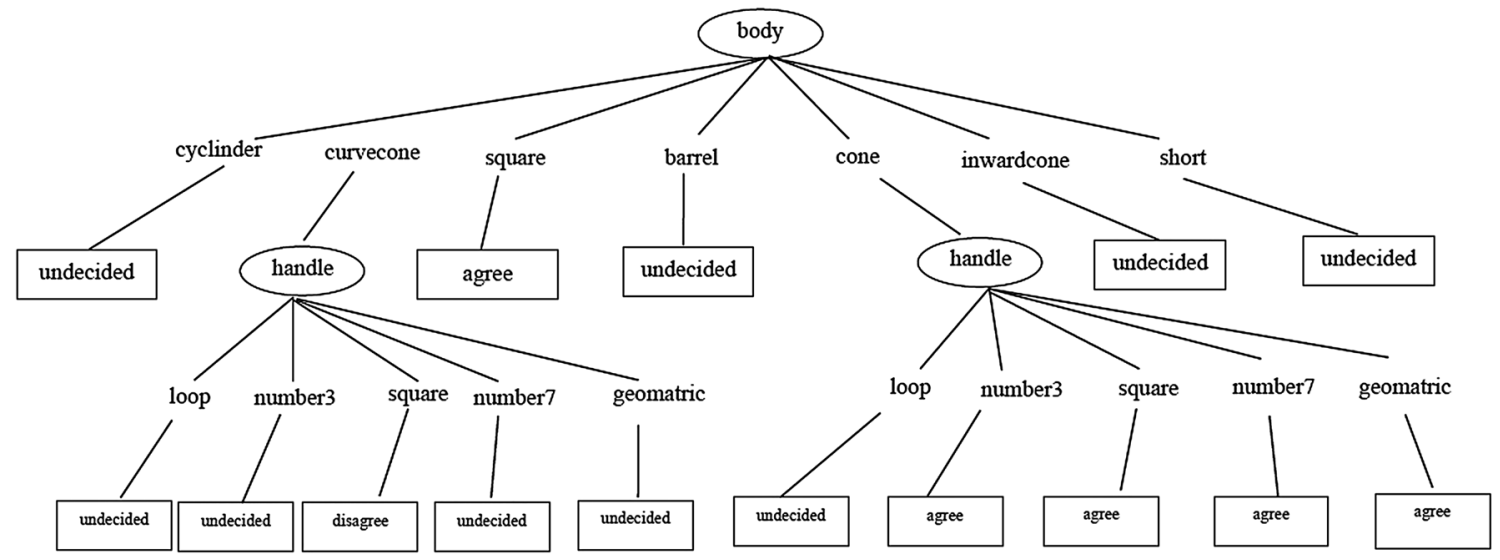

Fig. 5 Decision tree classifier for the emotion of ease of drinking

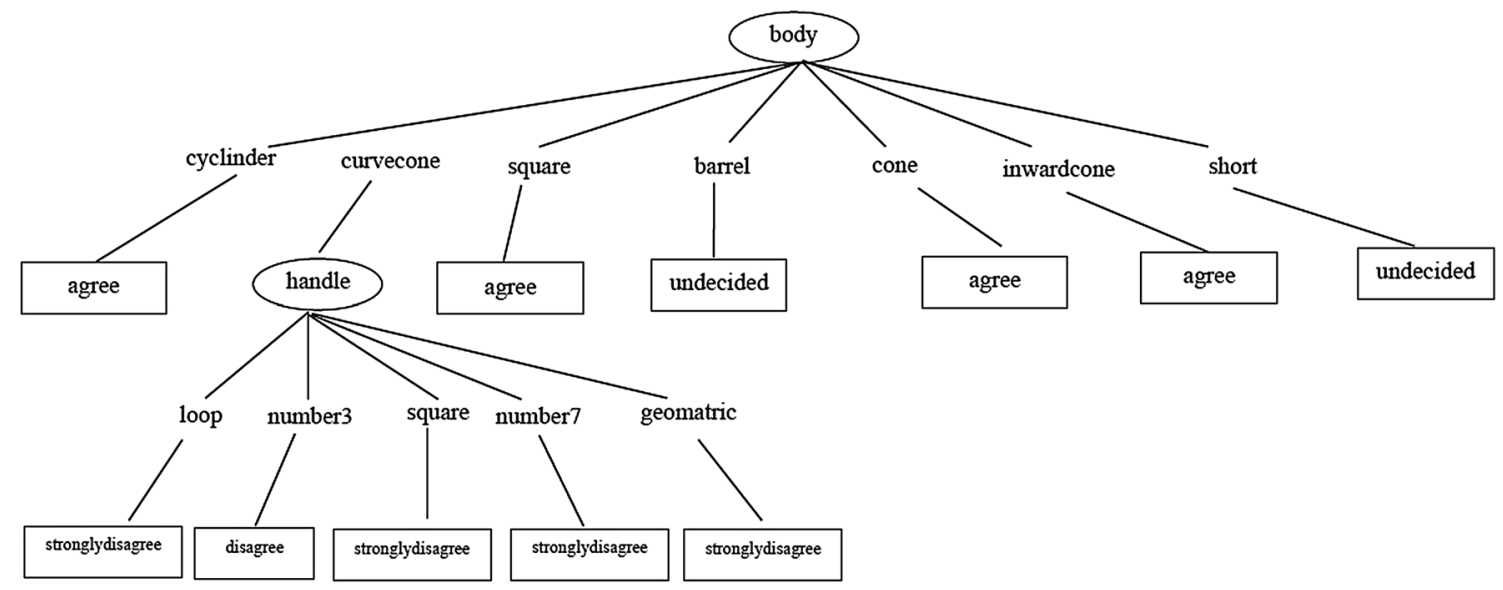

Fig. 6 Decision tree classifier for the emotion of ease of handing 


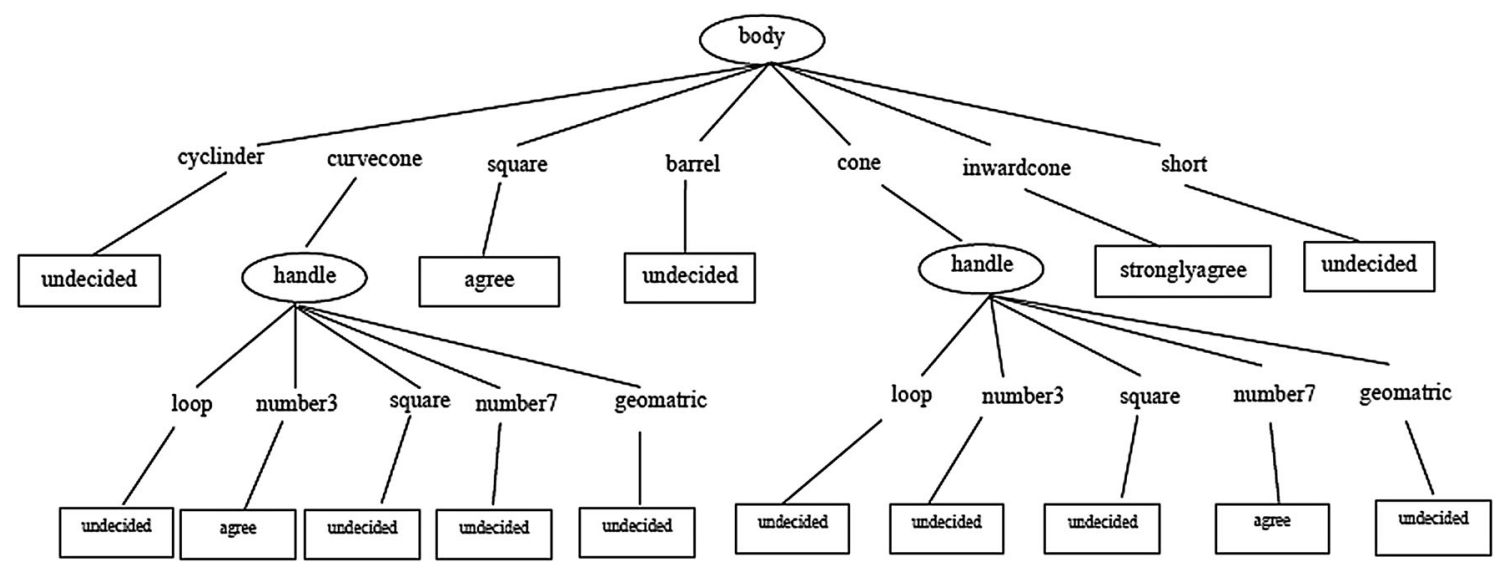

Fig. 7 Decision tree classifier for the emotion of modern

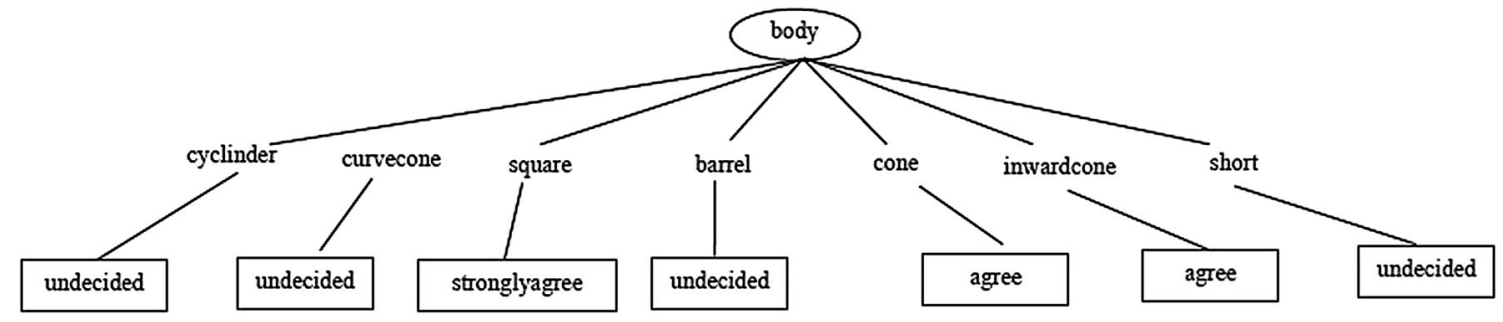

Fig. 8 Decision tree classifier for the emotion of quality

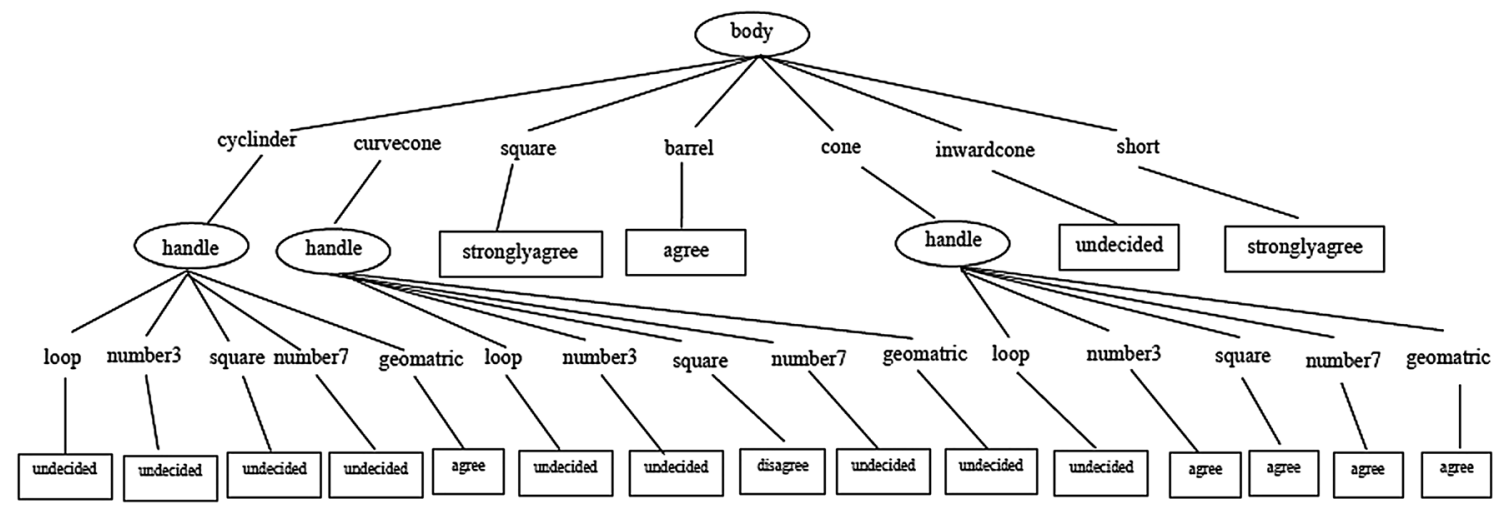

Fig. 9 Decision tree classifier for the emotion of durable

shows the most important category of mug that affecting the high degree of emotions/Kansei words (from agree to strongly agree level).

For CAR, the minimum of confidence value and the support value were determined as 0.1 . According to the high degree of emotion (from agree to strongly agree level), the most important rules are show in Table 6. For example, the bright color of mug is the design attribute that had the most relationship with the emotion of attractive with the confidence degree of 0.28 . The second most relation was the non-foot mug with the confidence degree of 0.24 . The non-pattern mug was the third most related this emotion with the confidence of 0.23 .

From the results of J48 and CAR, we found the difference of the predictive model of product property that affecting the emotions. For example, the most important properties of mug that affecting the emotion of attractive by J48 was body, handle and pattern whereas the most important properties by CAR was foot, lip, color and pattern. The non-pattern appearance was significant both of models, therefore the designers were able to design this attribute related to this customer emotion. Similarly, the 


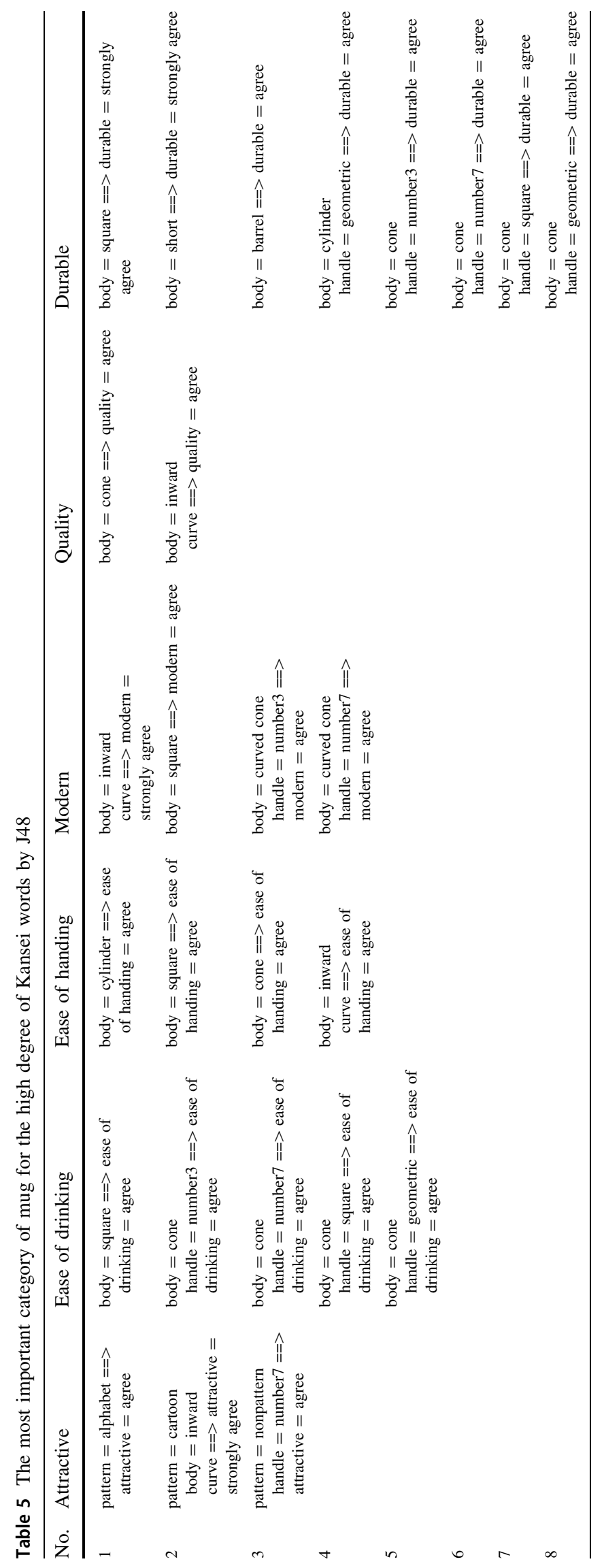




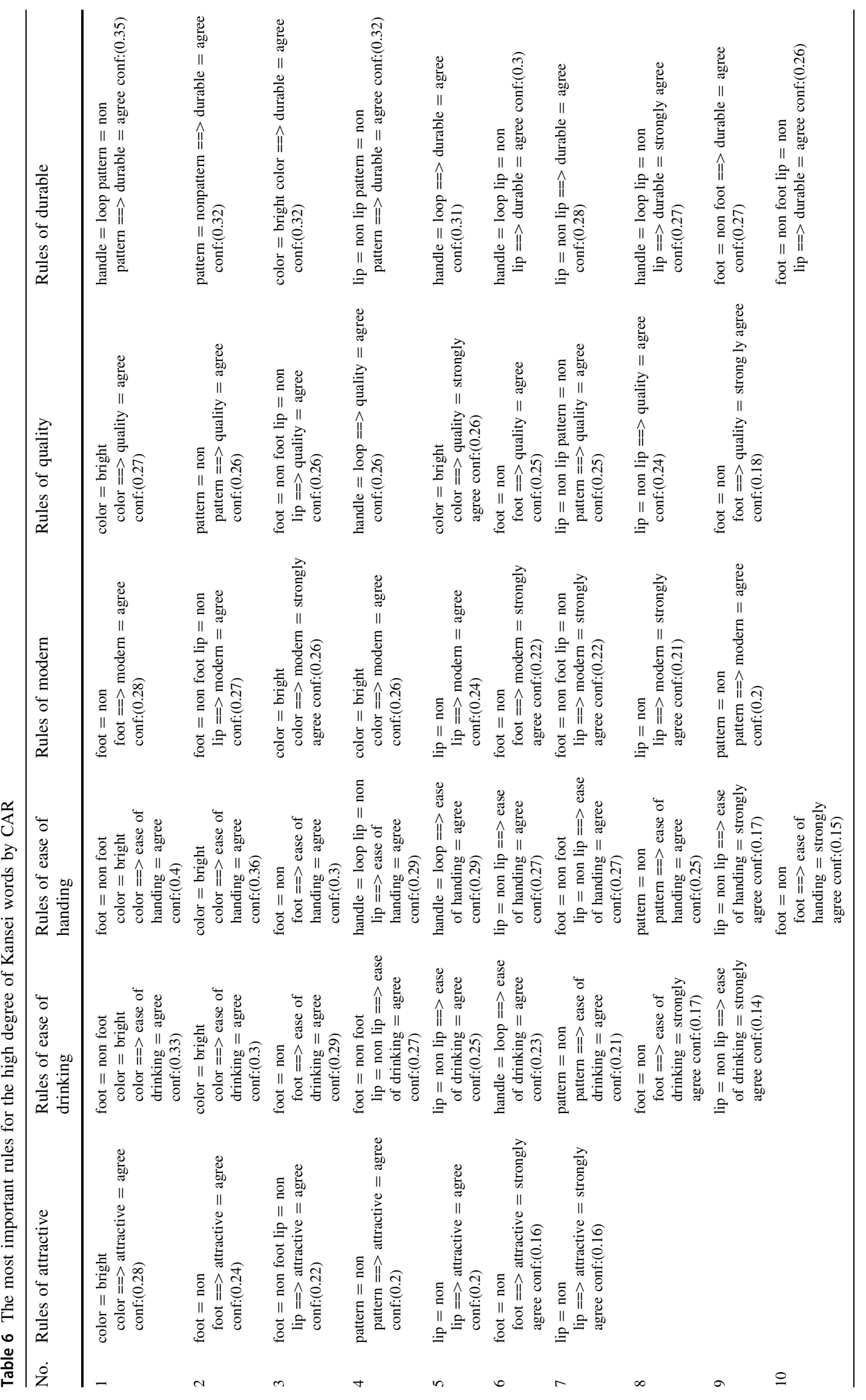


designers should develop the new product design by the suggested results for the other emotions. However, this study still in the initial step and there are various decision variables of Data Mining to be depth study such as algorithms (Support vector machines, Naive Bayes, k-means) and quality measures (conciseness, coverage, reliability). In addition, more the study on the psychological effect is needed.

\section{Conclusions}

Even though several popular techniques in product design and other related research theories are very helpful for designers in considering customer needs and evaluating design alternatives, they may not have efficiency and effectiveness. It might be due to current product design decisions in most industries still continue to be based on the experiences of designers. This study is investigated the product properties affecting the customer emotions by using KE, classification and association rule which are data mining methods. Decision tree J48 and CAR which are the most popular data mining methods are used to generate a predictive model and to find the appropriate rules. The results will be important not only for the mug design that affecting the customer emotions but also for other products in applying data mining methods in product design and development.

Open Access This article is distributed under the terms of the Creative Commons Attribution 4.0 International License (http://creative commons.org/licenses/by/4.0/), which permits unrestricted use, distribution, and reproduction in any medium, provided you give appropriate credit to the original author(s) and the source, provide a link to the Creative Commons license, and indicate if changes were made.

\section{References}

Analysis Services (2017) Training and Testing Data Sets. https:// msdn.microsoft.com/en-us/library/bb895173.aspx Accessed 30 Jan 2017

Berry MJA, Linoff GS (1997) Data mining techniques: for marketing, sales, and customer support. Wiley, New York

Chuan NK, Sivaji A, Shahimin MM, Saad N (2013) Kansei engineering for e-commerce sunglasses selection in Malaysia. Proc Soc Behav Sci 97:707-714

Faghihinia F, Mollaverdi N (2012) Building a maintenance policy through a multi-criterion decision-making model. J Ind Eng Int 8:14

Huang MS, Tsai HC, Huang TH (2011) Applying Kansei engineering to industrial machinery trade show booth design. Int J Ind Ergon 41(1):72-78

Huang Y, Chen CH, Khoo LP (2012) Kansei clustering for emotional design using a combined design structure matrix. Int J Ind Ergon 42(5):416-427
Jiao J, Zhang J, Halander Y (2003) A Kansei mining system for affective design. Expert Syst Appl 30(4):658-673

Kaya M, Keles AE, Oral EL (2014) Construction crew productivity prediction by using data mining methods. Proc Soc Behav Sci 141:1249-1253

Lia J, Shenb H, Topor R (2002) Mining the optimal class association rule set. Knowl Based Syst 15(7):399-405

Luo SJ, Fu YT, Korvenmaa P (2012) A preliminary study of perceptual matching for the evaluation of beverage bottle design. Int J Ind Ergon 42(2):219-232

Mehmanpazir F, Asadi S (2017) Development of an evolutionary fuzzy expert system for estimating future behavior of stock price. J Ind Eng Int 13:29-46

Nagamachi M (1995) Kansei engineering: a new ergonomic consumer oriented technology for product development. Int J Ind Ergon 15(1):3-11

Nagamachi M (2001) Kansei engineering: a powerful ergonomic technology for product development. In: Helander MG, Khalid HM, Tham MP (eds) Proceedings of the international conference on affective human factors design. ASEAN Academic Press, London, pp 9-14

Nagamachi M (2007) Perspectives and new trend of Kansei/affective engineering. In: International conference of quality management and organizational development. Helsingborg, Sweden

Natek S, Zwilling M (2013) Student data mining solution-knowledge management system related to higher education institutions. Expert Syst Appl 41(14):6400-6407

Pitaktiratham J, Sinlan T, Anuntavoranich P, Sinthupinyo S (2012) Application of Kansei engineering and association rules mining in product design. World Acad Sci Eng Technol 69:175-180

Rezki Nafissa, Kazar Okba, Mouss Leila Hayet, Kahloul Laid, Rezki Djamil (2016) On the use of multi-agent systems for the monitoring of industrial systems. J Ind Eng Int 12:111-118

Schütte S (2013) Evaluation of the affective coherence of the exterior and interior of chocolate snacks. Food Qual Prefer 29(1):16-24

Schütte S, Eklund J (2005) Design of rocker switches for workvehicles-an application of Kansei engineering. Appl Ergon 36(5):557-567

Shieh MD, Yeh YE (2013) Developing a design support system for the exterior form of running shoes using partial least squares and neural networks. Comput Ind Eng 65(4):704-718

Tang CY, Fung KY, Eric WML, Ho GTS, Kin WMS, Mou WL (2013) Product form design using customer perception evaluation by a combined super ellipse fitting and ANN approach. Adv Eng Inf 27(3):386-394

University of Waikato (2015) WEKA machine learning project. http://www.cs.waikato.ac.nz/ml/index.html Accessed 9 June 2015

Wikipedia (2015) C4.5 algorithm. http://en.wikipedia.org/wiki/C4.5_ algorithm Accessed 26 June 2015

Wikipedia (2015) Association rule learning. http://en.wikipedia.org/ wiki/Association_rule_learning Accessed 10 June 2015

Wikipedia (2015) Confusion matrix. http://en.wikipedia.org/wiki/ Confusion_matrix Accessed 10 June 2015

Yang S, Nagamachi M, Lee S (1999) Rule-based inference model for the Kansei engineering system. Int J Ind Ergon 24(5):459-471

Yang X, Wu D, Zhou F, Jiao J (2008) Association rule mining for affective product design. In: Proceedings of the 2008 IEEE International conference on industrial engineering and engineering Management, Singapore, pp 743-747

Zayed N, Awad AB, Akel WE, Doss W, Awad T, Radwan A, Mabrouk M (2013) The assessment of data mining for the prediction of therapeutic outcome in 3719 Egyptian patients with chronic hepatitis C. Clin Res Hepatol Gastroenterol 37:254-261 